\title{
EL DESAGRADO EN LA ESTÉTICA DE LO COTIDIANO
}

\section{DISPLEASURE IN EVERYDAY AESTHETICS}

\author{
Ma Jesús Godoy Domínguez* \\ UNIVERSIDAD DE SEVILLA
}

\begin{abstract}
Resumen: En el horizonte actualmente expansivo de la disciplina estética, el objetivo de este trabajo es aproximar dos realidades estéticas tradicionalmente desatendidas, como son las emociones negativas, por un lado, despreciadas por la estética moderna en tanto no placenteras, y la estética de lo cotidiano, por otro, ignorada igualmente por centrarse en los objetos utilitarios y las experiencias de tipo práctico. El fin en realidad es doble, porque no sólo se trata de rescatar estos dos ámbitos para la reflexión estética, sino de entrecruzarlos para ver el tratamiento que reciben los afectos negativos en el marco de la estética de lo cotidiano, si tienen acogida en ella o no. Para ello, abordaremos algunos de los teóricos más destacados de este reciente ámbito estético para comprobar en qué medida han podido superar los viejos prejuicios contra el displacer.
\end{abstract}

Palabras Clave: estética moderna, emociones negativas, estética de lo cotidiano, placer, displacer, estética contemporánea.

* Profesora Titular del Departamento de Estética e Historia de la Filosofía de la Universidad de Sevilla. E-mail: godoydom@us.es 
АвSTRACT: In the currently expansive horizon of the discipline of aesthetics, the aim of this work is to approach two traditionally neglected aesthetic realities, such as negative emotions on one hand, despised by modern aesthetics as not pleasant, and everyday aesthetics on the other, also ignored for focusing on practical objects and experiences. Our purpose is actually twofold, because it is not only to rescue these two areas for aesthetic reflection, but also to cross them to see the treatment received by negative affects within the framework of the aesthetics of everday life, if they are welcomed or not. To this end, we will address some of the main theorists of this recent aesthetic field to study how far they have been able to overcome the old prejudices against displeasure.

KEYwORDs: modern aesthetics, negative emotions, everyday aesthetics, pleasure, displeasure, contemporary aesthetics.

\section{Introducción}

En los últimos tiempos, la estética ha visto ampliar considerablemente su ámbito de estudio gracias a nuevos dominios que han venido a expandir el limitado enfoque de esta disciplina desde su establecimiento en el siglo XVIII. Es lo que ha ocurrido con las llamadas "emociones negativas", cuyo interés para los estudiosos del fenómeno estético ha ido mucho más allá del mero intento de explicar este aspecto de nuestra vida afectiva descuidado en gran medida en el pasado, derivando así en una auténtica dignificación de estados emocionales como el horror, la vergüenza o el asco, que nunca fueron acogidos ciertamente dentro de la estética moderna ${ }^{1}$. Pero ha ocurrido también con la emergente "estética de lo cotidiano", que teniendo por finalidad los objetos corrientes y procesos normales de la vida, ha promovido su recuperación para el terreno reflexivo y, de ese modo, su revalorización como acreedores igualmente de atención estética. Con objetos de estudio dispares, pero compartiendo una misma estrategia inclusiva, ambos campos de investigación han llevado a la disciplina estética a revisar sus antiguos supuestos y a afrontar, en último extremo, un tipo de experiencias y un tipo de objetos y situaciones no previstos inicialmente en

\footnotetext{
${ }^{1}$ Como en todo, siempre hay excepciones: una sería el miedo, en el seno de la experiencia estética de lo sublime -desarrollada por Burke y Kant- y otra la pena, en el de la tragedia aunque en el contexto aún de la estética clásica y según la antigua teorización aristotélica-.
} 
su agenda, pero con los que ha conseguido enriquecer y actualizar sin duda sus planteamientos ${ }^{2}$.

Este enriquecimiento se entiende mejor si nos dirigimos a la adversa situación de partida de cada uno de esos dominios, hoy -insistimos- crecientemente superada: en el caso de los afectos negativos, el discurso estético moderno los rechazó como respuesta estética legítima en el momento de trasladar la belleza a la interioridad subjetiva, o sea, cuando la identificó con el sentimiento de placer, que quedó connotado así como "positivo" -en la única respuesta estética reconocida en realidad-, frente al displacer o dolor, etiquetado a su vez como "negativo" -y, por ende, estigmatizado y desechado-. Quiere decirse que los afectos negativos fueron designados así estrictamente como "no placenteros" por el simple hecho de contraponerse a las emociones que tuvieron las de ganar-las placenteras, lógicamente- y con las que nunca estuvieron en pie de igualdad. En el caso de la estética de lo cotidiano, la estética moderna se encargó también de que sólo el arte -sobre todo, a partir y por medio de $\mathrm{Hegel}^{3}$ - contara para el pensamiento, al ser lo único que provocaba una experiencia superior y privilegiada, una experiencia de cariz contemplativo y desinteresado -"una experiencia" sin más, en expresión del padre, para muchos, de esta pujante rama de la estética, John Dewey (1949: 34)-, que sacando de la existencia ordinaria permitía olvidarse de ella por unos momentos. Fue así como los objetos utilitarios y las experiencias de tipo práctico, consideradas de segundo grado en comparación con las artísticas fijadas como modelo, acabaron siendo desterradas asimismo del interés estético primordial.

Pero si por algo hemos reparado en estas dos nuevas líneas de trabajo dentro de la estética actual es por el propósito que nos guiará en estas páginas, que es abordar los afectos negativos en el marco hasta hace poco inexistente de la estética de lo cotidiano. Dentro del horizonte expansivo antes mencionado, pretendemos aproximar estas dos realidades históricamente desatendidas a fin de comprobar si la estética de la cotidiano, en su afán por rescatar para la discusión

\footnotetext{
${ }^{2}$ Compartimos así, dentro de la estética de lo cotidiano, las tesis de Yuriko Saito, en su pretensión de ampliar y completar el discurso estético tradicional (2017: 1-5, 30-31; 2007: 52-53), como desde fuera ya, de esta rama de la estética, vienen haciendo pensadores como Jacques Ranciére (2011).

${ }^{3}$ Desde el mismo pórtico de sus Lecciones de estética, deja constancia Hegel del giro estético producido, fruto del cual quedaría para siempre atrás el territorio habitual de la belleza durante siglos: "Estas lecciones están dedicadas a la Estética, es decir, a la filosofía o ciencia de lo bello, y más precisamente de lo bello artístico. Excluimos lo bello natural” (2015: 49).
} 
teórica formas de experiencia negadas desde antaño por no dar la talla de lo artístico, brinda la hospitalidad que cabría esperar de ella, en tanto estética aperturista e integradora, de cariz reivindicativo, a las emociones desapacibles ${ }^{4}$; al fin y al cabo, experiencias estéticas insatisfactorias como escuchar el ruido del tráfico o contemplar -y oler- basura en las calles son experiencias que formando parte de nuestra vida diaria parece que debieran tener cabida en una estética orientada a lo mundano 5 . Con estas miras, indagaremos en las propuestas de algunos de los principales valedores de este reciente ámbito estético para comprobar a qué tipo de experiencia se refieren realmente cuando hablan de "lo cotidiano" y, en ese sentido, en qué medida han podido superar los prejuicios de la estética convencional.

\section{La placentera cotidianeidad}

Para ello, partiremos de las dos modalidades de la estética de lo cotidiano que ha distinguido Chris Dowling (2010): la "débil" y la "fuerte", que podemos identificar con Thomas Leddy y Yuriko Saito respectivamente. La primera acomoda los conceptos estéticos, de inspiración eminentemente artística hemos dicho, a los objetos y acciones comunes, no-artísticos por tanto, que extraídos de sus contextos funcionales, pasan a ser regulados por los mismos criterios que han venido regulando el arte a lo largo de los dos últimos siglos y que acabaron haciendo de él algo extraño, diferente e inusual. La segunda variante afronta, por el contrario, los objetos y acciones de todos los días como lo que realmente son, objetos y acciones nada especiales, como no lo son desde luego ni una tostadora ni pintar la casa. Como consecuencia de ello, la versión "débil" potencia la experiencia extraordinaria de los artefactos y procesos normales de la vida,

\footnotetext{
${ }^{4}$ Por estas emociones, entendemos un amplio espectro afectivo que va desde un sutil desagrado hasta la aversión más absoluta, todo ello englobado bajo la denominación común de "displacer".

${ }^{5}$ Hacemos énfasis intencionado en la experiencia de tipo olfativo, desestimada también por el discurso estético académico debido al prejuicio tradicional contra los sentidos más corporales (olfato, gusto y tacto frente a vista y oído). Afortunadamente, son cada vez más los estudios que intentan devolverle al olfato su condición estética, como los de Emily Brady (2005) y Carolyn Korsmeyer (2002) y, dentro ya de nuestras fronteras, el de Marta Tafalla (2013).
} 
mientras la "fuerte" toma la cotidianeidad como pura y simple cotidianeidad, con todo su carácter instrumental y utilitario que no sólo no elude, sino que fomenta y persigue. Por eso, la experiencia estética en la primera modalidad, de "cotidiana" como tal, tiene bastante poco, por no decir nada, ya que se trata de una experiencia exactamente como la del arte, sólo que en lugar de producirse en el recinto apartado de un museo, tiene lugar en nuestra casa por ejemplo mientras cocinamos; una actividad a la que inviste así de la excepcionalidad de la que por propia esencia carece, a la que rescata de su condición irrelevante y tediosa -nada estética, desde este enfoque y, por tanto, negativa- y reviste de grandeza y significado al dotarla de "aura", que según Leddy es lo que hace que la consideremos finalmente estética: propicia que le demos una entidad mayor de la que en verdad tiene, que irradie una especie de resplandor y todo en ella parezca singularmente intenso (Leddy, 2012: 132-135, 142-143). En suma, que el objeto común, la actividad corriente, saliendo del ámbito de lo ordinario hacia lo extraordinario, experimentándolos como nunca antes los habíamos experimentado, resultan tan positivos y placenteros como lo ha venido siendo históricamente el arte.

En su deseo de preservar la experiencia cotidiana como propiamente "cotidiana", la segunda modalidad, la "fuerte", quiere evitar a toda costa precisamente que lo banal, lo monótono y aburrido de esa experiencia, lo negativo y poco agradable de la misma, pueda perderse; es más, la voluntad, según explica Saito, es llevar hasta el radar estético todo lo que en nuestra rutina diaria pasa desapercibido porque lo hacemos -si se trata de una acción- o tenemos contacto con él -si es un artilugio- de manera automática y sin prestarle atención (Saito, 2017: 24-25). El objetivo es concentrarse en aquellos aspectos que de otro modo desaparecerían en el trasfondo de la existencia ordinaria, desarrollar una sensibilidad estética más aguda para poder apreciar -saborear, dice textualmente Saito (2017: 38; 2007: 31) - todas las facetas de la vida, estén ligadas o no al arte; una sensibilidad al mismo tiempo más abierta para acoger dentro, una parte al menos, de lo que en otro tiempo quedó fuera por no responder al criterio artístico dominante.

Nos interesa sobre todo cómo, pese a sus diferencias, ambas caracterizaciones de la estética de lo cotidiano, a través de sus respectivos promotores, le abren hueco a las emociones negativas mediante propiedades estéticas desacostumbradas -desde el punto de vista estético tradicional, se sobreentiende-como "aburrido" e "insustancial", "sucio" y "desordenado", incluso "ofensivo" y "repugnante"; aunque la salida que se les da después, como tendremos ocasión de 
ver, es distinta en cada caso. Pero es importante tener en cuenta ya este hecho, considerar que tanto Leddy como Saito se hacen cargo de numerosos rasgos estéticos negativos, expresión a su vez de las emociones negativas, mientras que otros estetas de lo cotidiano se ciñen rigurosamente a los afectos positivos, planteando así la experiencia estética como la experiencia placentera al uso. Lo hace Arto Haapala por ejemplo, desde las filas de la variante "fuerte" -la de Saito, para entendernos-: su teorización de "lo familiar" y "lo hogareño", como señas de identidad de lo cotidiano stricto sensu, en contraste con lo extraño y memorable de lo cotidiano elevado a extraordinario, es de rotundo signo positivo. Se explica así que, para él, aun cuando los objetos con los que nos relacionamos en el día a día carecen de la frescura típica de lo excepcional y pueden ser caracterizados así negativamente -porque les falta algo: novedad, interés o lo que sea-, resultan paradójicamente agradables por la sensación de confort y estabilidad que proporcionan, sensación de sentirnos "a salvo" y definitivamente en casa ${ }^{6}$.

Positivamente, describe asimismo Jane Forsey la experiencia estética, recalando en el aspecto eminentemente práctico de lo cotidiano y añadiendo nuevos matices con ello a las observaciones de Haapala ${ }^{7}$. Porque en Haapala, lo hogareño y familiar es lo que funciona bien y, funcionando bien, es también lo que pasa inadvertido generalmente ante nuestra mirada. Un objeto cualquiera, una herramienta como el martillo -siguiendo el ejemplo de Haapala, basado a su vez en el de Heidegger ${ }^{8}$-, deviene así placentero cuando responde perfectamente a su función, aunque ello suponga -y precisamente por eso es positivodisolverse en ella y desaparecer, de paso, de nuestro radar estético, al decir de Saito. De hecho, el martillo ya no tiene ningún interés estético para Haapala cuando deja de funcionar porque entonces llama la atención y pasa de familiar, a ajeno y extraño, rasgos de los que el teórico finlandés rehúye expresamente, en su adscripción a lo cotidiano como puramente cotidiano. En este punto es donde interviene Forsey para reformular lo casero y familiar de Haapala -que a todas luces comparte- desde una idea distinta de la "carencia" - de la que disiente, en cambio, completamente-, pues termina sumiendo al objeto en una falta absoluta de aptitud para hacerse notar. Frente a estos postulados, sostiene

\footnotetext{
${ }^{6}$ La definición exacta de Haapala para este placer es la de una "tranquila fascinación por la ausencia de requerimientos visuales, auditivos o del tipo que sean a nuestro alrededor" (2005: 52). Traducción propia, como todas las que aparecerán a lo largo de este trabajo.

${ }^{7}$ Precisamente porque la autora se centra en la estética del diseño, sus conclusiones son aplicables a la estética de lo cotidiano, como ella misma recalca y lleva a cabo en uno de sus textos (Forsey, 2013a).

${ }^{8}$ En su obra de 1927, Ser y tiempo.
} 
Forsey que lo que funciona de manera óptima capacita ya al objeto para atraer nuestra mirada sin hacerle abandonar en ningún momento su naturaleza instrumental. Asegura en este sentido la autora que sólo en el contexto utilitario de una cafetera -siendo consumidor habitual de café y utilizándola a menudo, por tanto- puede valorarse estéticamente su capacidad para superar el funcionamiento estándar de la misma. La valoración estética aquí, como es fácil suponer, es una vez más de valencia positiva, coincidiendo al final así, queriendo o sin querer, con Haapala: la cafetera que funciona extremadamente bien es excelente estéticamente, por lo que no es placentera, es muy placentera'. Se desecha de antemano entonces la cafetera que, o no funciona, o funciona mal o regular, pues aunque llamando la atención también, no lo hace por sus méritos o sus virtudes, sino por sus defectos, por resultar displacentera en definitiva; de ahí la máxima de Forsey en aras de la experiencia estética de siempre: "cumplir con su función es el requisito mínimo para que un objeto utilitario pueda ser candidato a la apreciación estética" (Forsey, 2013a: 243) ${ }^{10}$.

En realidad, la propuesta placentera de Forsey entronca con la de Glenn Parsons y Allen Carlson (2012), radicada asimismo en el carácter funcional del objeto. Partiendo de la belleza utilitaria sobre la que discurriera Hume -frente a la belleza desinteresada de ascendencia kantiana que acabó triunfando históricamente-, pero haciendo hincapié de todos modos en la cuestión formal, en la belleza propiamente dicha, estos dos teóricos dejaron establecido que un artefacto es estéticamente bueno cuando la forma con la que está diseñado parece adecuada -looks fit-a la función que ha de cumplir; algo que es posible valorar por el conocimiento previo del objeto y de la utilidad para la que está destinado. Es lo que hace, exponen gráficamente los autores, que un coche de carreras con un alerón resulte atractivo porque lo hace aerodinámico-porque le permite adecuarse, a fin de cuentas, a la acción de correr que le presuponemosy no lo parezca, en cambio, un coche fúnebre, donde no teniendo cometido alguno ese elemento, lo juzgamos poco agraciado. Sea como fuere y para lo que aquí nos interesa, las emociones positivas vuelven a ser la meta de la experiencia estética: "generalmente hablando, la gente encuentra placenteros los objetos que parecen adecuarse perfectamente a su función” (Parsons y Carlson, 2012: 101).

\footnotetext{
${ }^{9}$ No en vano, a Forsey parece molestarle la reducción que hace Haapala de lo que para ella es un placer sin paliativos a una "tímida satisfacción" -"quiet satisfaction" (Forsey, 2013a: 242) ${ }^{10}$ Saito contempla, sin embargo, el supuesto contrario, que el objeto tenga un funcionamiento pésimo -en lugar de óptimo- y produzca así una experiencia estética insatisfactoria (Saito, 2007: 211-213). Para ella además, el requisito mínimo para la apreciación estética es la atención que se le presta al objeto (2017: 24).
} 
Aun así y respecto a Forsey y Haapala, hay una diferencia importante en Parsons y Carlson, pues aunque tímidamente -dedicándole un espacio casi residual en el total de su obra ${ }^{11}$-, asoman ya en sus reflexiones las emociones negativas a través de aquellos utensilios que demuestran abiertamente no adecuarse a su función, caso de una bicicleta sin sillín o de un coche con las ruedas desinfladas; objetos, según los autores, que no debieran complacer estéticamente al contravenir la regla anterior, que era -recordemos- que lo que sí se ajusta, sí complace. Pero aun haciéndole sitio, se apresuran a matizar este segundo supuesto, señalando que es bastante menos plausible que el primero -lo que equivale a restar valor finalmente al displacer, para entregárselo, como no podía ser de otro modo, a la complacencia- y arguyendo que hay múltiples objetos inadecuados a su función que, pese a ello, no desagradan, que "no parecen estéticamente pobres” (Parsons y Carlson, 2012: 109); más aún, que despiertan auténtico furor estético. Basta dirigirse al mundo de la moda para comprobarlo, dicen los autores: unos zapatos con tacón de aguja, que dejan además el pie al descubierto, no sólo no lo protegen, sino que dificultan la acción de caminar, que son las dos funciones que cabe pedirle a un zapato. No obstante y lejos de producir insatisfacción, pueden satisfacer y mucho, porque es posible eludir momentáneamente el carácter instrumental del objeto y centrarse en sus aspectos más puramente sensibles -forma, tamaño, color, textura-, de manera que lo que no se adapta a su función puede acabar resultando igual de placentero que lo que sí lo hace ${ }^{12}$.

Desde este enfoque, para Parsons y Carlson no habría una "fealdad funcional" homologable a la belleza funcional sobre la que ellos discurren, sencillamente porque el descontento, aunque con cierta presencia en su discurso, no consigue ponerse al mismo nivel, ni mucho menos, que el goce, que sigue llevando las de ganar estéticamente, incluso cuando el objeto desatiende la utilidad para la que fue creado. El regocijo está llamado a borrar así todo rastro de insatisfacción - no por casualidad, la tesis sobre la que gravitan ambos pensadores es la "belleza" - y lo hace con ayuda de la forma, que se las arregla para hacer al final de lo negativo algo positivo. Esta flagrante anulación de lo negativo nos remite a la denominada "paradoja de la tragedia", que articulada

\footnotetext{
${ }^{11}$ Apenas un capítulo de cuatro páginas titulado "The Aesthetics of Dysfunction” (2012: 107110).

${ }^{12}$ El ejemplo paradigmático aquí son quizás los zapatos de Manolo Blahník, auténticos objetos de culto, en torno a los cuales se montó recientemente una exposición en el Museo Nacional de Artes Decorativas de Madrid (noviembre 2017-marzo 2018).
} 
en torno a la afectividad no placentera viene a decir que, mientras que en la vida real tendemos a evitar las emociones fastidiosas y poco agradables, parece que nos sentimos atraídos por ellas y hasta las disfrutamos cuando nos las procura el ámbito estético -el arte y la ficción, concretamente, según el antiguo pensamiento que se remonta a Aristóteles ${ }^{13}$-; ámbito éste que tiene la virtud así de convertir lo inicialmente molesto en cautivador; lo negativo, en positivo. Si bien esta paradoja está pensada originalmente para el mundo autónomo del arte en su contraposición al mundo práctico real, entendemos que su extrapolación a la estética de la cotidiano no reviste mayores problemas en tanto que, por encima de todo, es estética y atiende en ese sentido al componente perceptivo y sensible de los objetos (Saito, 2007: 9), que es el que cobra relieve en dicha paradoja, como veremos a continuación.

Lo interesante para nosotros es que, de las tres explicaciones fundamentales ofrecidas a este fenómeno -dos clásicas y una más actual ${ }^{14}-$, y que iremos desgranando al hilo de nuestra exposición, la que se ajustaría mejor a la belleza funcional de Parsons y Carlson es la de la compensación, que es, entre otros autores, la de Diderot ${ }^{15}$. En ella, la emoción negativa que despierta la expresión estética -artística, si se quiere- es como tal desabrida, pero se "repara" ese efecto adverso -se suprime su negatividad-otorgando al mismo tiempo algún tipo de recompensa que restablece el equilibrio, es decir, que la reconduce hacia lo positivo. En estos términos, interpreta Diderot el cuadro de Chardin La raya $(1728)^{16}$, al mostrar en pleno centro de la composición el pez que le da nombre abierto en canal y, de ese modo, desangrándose y mostrando sus vísceras. Diderot habla de la maestría de Chardin y de la "magia" del lienzo en el sentido de que "redimen" el objeto representado mediante la manera realista de representarlo, de que desvían la atención del plano del fondo - del despedazamiento y desangramiento, sumamente desagradables, si no repulsivos- hacia el plano de la forma, asimilada a belleza y, en consecuencia, a satisfacción. Salvando las

\footnotetext{
${ }^{13}$ Aludiendo Aristóteles a lo que sucede en la tragedia, expone cómo el espectador empieza siendo presa del sentimiento de pena o lástima, provocadas por su identificación empática con los personajes que ve sufrir en escena, pero termina liberándose de ellas y sintiendo gratamente -un gran alivio en realidad o liberación catártica- al comprender que es sobre ese otro ficticio y no sobre él mismo como sujeto real sobre quien recae el mal causante de tanto sufrimiento (Poética, 1453b10-15).

${ }^{14}$ Siguiendo a Jerrold Levinson (2015, 68-71).

15 También la de Aristóteles y Dubos, pero Diderot se aproxima más a lo que aquí pretendemos.

16 En el Salón de 1763 (Diderot, 1994: 54).
} 
distancias -en un caso se trata, obviamente, del insigne objeto artístico y en el otro, de un objeto vulgar y corriente-, es lo que sucedería, hasta cierto punto también, con el utensilio de Parsons y Carlson que en un momento dado deja de serlo, pues el displacer ocasionado por su falta de aptitud se ve compensado por la forma con la que está diseñado - por la destreza de la que hace gala el maestro zapatero por ejemplo, a semejanza del maestro pintor $^{17}$-, que haciendo las veces de escudo protector contra el desagrado, logra que la experiencia, pese a todo, sea gozosa.

\section{Displacer embellecido}

Para acceder a las otras dos explicaciones a la "paradoja de la tragedia" dentro de la estética de lo cotidiano, hay que dirigirse a Yuriko Saito y Thomas Leddy, quienes se hacen eco sin tapujos de las emociones negativas, aunque de manera distinta entre sí, que es diferente a su vez de la que hemos visto en Parsons y Carlson. Para empezar, el motivo de fricción entre ambos pensadores tiene que ver, naturalmente, con su noción discrepante de lo cotidiano, que en el caso de Saito, en su reivindicación de lo cotidiano como específicamente cotidiano, le lleva a reclamar un nuevo estatuto y una nueva consideración para las experiencias poco gratas de la existencia ordinaria como lo monótono, lo aburrido y lo banal; experiencias, para Saito -a diferencia de Leddy, como veremos-, plenamente estéticas, pero estéticas en un sentido distinto del habitual, más neutral y también más genuino -porque lo estético estuvo vinculado inicialmente a lo sensible, argumenta Saito, y no tanto a lo placentero que vino después ${ }^{18}-$. En palabras de la japonesa: "puede que no sea placentera, memorable o especial, pero esta rutina de todos los días da la textura estética -en sentido neutral- de la vida ordinaria" (Saito, 2017: 27). Sin embargo y aun poniendo en evidencia así la estrechez de miras de la estética moderna, a lo que aspira realmente Saito cuando habla de neutralidad es a que los fenómenos estéticos a los que solemos

\footnotetext{
${ }^{17}$ Esa maestría en su confección es lo que ha llevado a dar personalidad propia a los zapatos de Manolo Blahník, identificándolos escuetamente como "Manolos". Se habla así de que "me he comprado unos Manolos", al igual que se habla de haber adquirido "un Picasso".

${ }^{18} \mathrm{El}$ argumento aquí es que cuando Baumgarten fundó la estética a mediados del siglo XVIII, la definió como ciencia del conocimiento obtenido por medio de los sentidos, nada más. En este aspecto, coinciden totalmente Saito (2017: 179) y Korsmeyer por ejemplo (2011: 126).
} 
ser inmunes, los "momentos valle" como ella los llama (Saito, 207: 48), puedan ser igual de positivos que los "momentos cumbre" o fuera de serie -lo bello y lo sublime, principalmente- al conformar el grueso de nuestra vida estética e ir acompañados frecuentemente de una acción ${ }^{19}$. Pretende hacer así de lo bonito, lo limpio y lo ordenado -que no son negativos, sino negados por ignorados-, pero sobre todo de lo tedioso, lo insulso y anodino - negativos ya de pleno derecho por poco o nada satisfactorios- una experiencia estética positiva, menos intensa y poderosa sin duda que lo cotidiano elevado a extraordinario, pero en todo caso positiva en tanto placentera ${ }^{20}$; aun así, la teórica es consciente de que este cambio de paradigma estético que ella persigue, similar al que tuvo lugar cuando lo sublime y lo pintoresco vinieron a completar a lo simplemente bello -mediante el enaltecimiento de cualidades inéditas en aquel entonces como irregular, desmesurado, rudo y caótico-, "requiere más evolución que revolución” (Saito, 2017: 207).

Esperando que lo negativo -junto a lo simplemente negado- devenga más pronto que tarde positivo, las tesis de Saito guardan cierto parentesco con la solución a la "paradoja de la tragedia" conocida como de la conversión, donde la respuesta afectiva incómoda se vuelve sin embargo deleitosa en el curso de la apreciación estética, según expone Hume en su análisis de la tragedia, elaborado conforme al discurso aristotélico; expresa al respecto el escocés que la complacencia del público durante la representación dramática es directamente proporcional a la aflicción que experimenta (Hume, 2011: 211-218). No obstante y aun siendo la razón de ser del disfrute, el malestar afectivo no dura más de lo necesario; tan pronto como el descontento ha sido activado y ha mostrado todo su potencial devastador, o sea, tan pronto como los acontecimientos trágicos representados han dado de sí, dan paso al alborozo que lo hacen desaparecer de inmediato; de ahí que ya no se trate de compensación, sino de una conversión en toda regla, porque no es que el placer compense el dolor del primer instante, es que el dolor se transforma en placer, es absorbido por él y, de ese modo, eliminado. Una estetización de esta naturaleza, o absorción de lo negativo por lo positivo, habría en el alegato de Saito en favor de aquellas experiencias como la que comporta el hacer la colada -la fragancia a ropa limpia, una vez hecha, pero

\footnotetext{
${ }^{19}$ Sobre todo, si son fenómenos negativos: una habitación desordenada, por ejemplo, invita a ordenarla.

${ }^{20}$ A juicio de Saito, "con algún esfuerzo y dedicación, podremos encontrar ciertamente valores estéticos positivos en objetos y propiedades normalmente consideradas negativas estéticamente" (2007: 203).
} 
también y en especial para nosotros, el tufo a ropa sucia, antes de hacerla ${ }^{21}-$, pues por poco estética e infravalorada que haya estado esta experiencia como irrelevante y cotidiana, la autora promueve su conversión en positiva e íntegramente estética. De hecho, para Saito, lo ordinario tiene un carácter estético propio, sólo que alejado de lo insólito y lo excepcional. Para descubrirlo, sólo hay que proyectar belleza - placer- en objetos y acciones que a primera vista no son bellos -son displacenteros-, que hasta parecen a años luz de serlo, siendo de gran ayuda para ello, según la autora, la educación estética ${ }^{22}$.

Si esto ocurre en Saito, con más razón aún podemos relacionar a Leddy con el argumento de la conversión, habida cuenta que en su caso la experiencia cotidiana tiene que volverse extraordinaria para poder ser estética. Traducido al lenguaje afectivo, esto quiere decir que lo trivial, lo soso y lo común sólo se desprenden de su negatividad y su naturaleza ordinaria, o sea, llegan a ser estéticos, por medio del "aura", que los cambia a positivos al hacerlos extraordinarios y, de ese modo, neutralizarlos. En palabras del propio Leddy: "lo cotidiano como propiamente cotidiano es irrelevante y aburrido y sólo es estético cuando es transformado" (2012: 112). Pero esta transformación, en contraste con la de Saito -quien al confiarla al paso del tiempo como en lo sublime y lo pintoresco, hace de ella un proceso largo y laborioso-, es sumamente rápida, inmediata incluso, porque es imposible acercarse estéticamente a lo cotidiano, afirma Leddy, sin provocar su paso automático a extraordinario; sin que esa aproximación, siendo como la que tiene lugar contemplando una escultura o escuchando una pieza de música, no desnaturalice en el fondo su esencia. Por tanto, con sólo reparar en el objeto doméstico o la acción común los liberamos de su prosaísmo habitual -negativo por escasamente placentero- y les damos, aun sin querer, la singularidad -y todo lo positivo- que por definición les falta; en resumidas cuentas, hacemos de ellos una obra de arte, una experiencia irrepetible, y los disfrutamos porque los rescatamos de su insuficiencia e insignificancia ${ }^{23}$.

\footnotetext{
${ }^{21}$ Saito dedica un capítulo entero de su último libro a esta actividad a fin de incorporarla a la reflexión estética por sus múltiples propiedades estéticas -visuales, olfativas, incluso táctiles-, tanto desde el punto de vista de la experiencia como también y, sobre todo, de su ejecución (2017: 115-138).

${ }^{22}$ La autora rememora aquí las Cartas sobre la educación estética del hombre de Schiller, de 1795 (Saito, 2017: 212-213).

${ }^{23}$ Leddy distingue expresamente este tipo de transformación, que no saca al objeto del entorno cotidiano, de la "transfiguración" de Danto, que sólo se da cuando el objeto es llevado dentro de los límites del arte, como ocurre por ejemplo con la Caja Brillo de Warhol (Leddy, 2012: 76 y 83-84).
} 
Gracias al "aura” y al cambio que produce en el objeto, Leddy parece mostrarse ciertamente receptivo con los fenómenos estéticos que se salen de la pauta del deleite. No en vano, su llegada a la estética de lo cotidiano, como él mismo relata (Leddy, 2012: 9), se produjo legitimando propiedades estéticas básicas -limpio, ordenado, recogido, junto a sus opuestos, sucio, desordenado, desorganizado-, que habiendo sido desdeñadas por la estética tradicional, se incorporaban por primera vez así a la reflexión filosófica ${ }^{24}$. Pero esa incorporación vendría posibilitada por la jerarquía establecida por el mismo Leddy años después -bajo influencia del mismo discurso que decía combatir y su obsesiva tendencia a la ordenación ${ }^{25}$ - dentro del llamado continuum estético, esto es, por los niveles en que iba a segmentar la experiencia estética según su grado de complejidad y que abarcaban desde el inferior, donde estaban las propiedades "superficiales" - a las arriba mencionadas, se sumaban además "perfecto" e "imperfecto", "equilibrado" y "desequilibrado", "puro" e "impuro"-, hasta el superior de propiedades más profundas y estructurales, como bello, sublime y elegante. Su noción de continuum estético era lo suficientemente holgada así como para albergar a todo ese nuevo elenco de propiedades, placenteras unas y otras no, pero todas ellas olvidadas frente a lo eminentemente positivo ${ }^{26}$. Ahora bien, lo sería por efecto del "aura", que lo que hacía era desactivar lo negativocotidiano y reconducirlo hacia lo positivo-extraordinario, lo único que cuenta y ha contado siempre en realidad para Leddy. Por eso, aunque asegurando coincidir con Saito en la necesidad de llevar a primer plano a los fenómenos estéticos cotidianos, en especial los insatisfactorios, reconoce también que nunca existirá completa simetría con los extraordinarios y placenteros, pues "la estética tiene más que ver con las cualidades positivas que con las negativas" (Leddy, 2012: 64). Lo negativo es estético, entonces, para Leddy en la medida en que puede

\footnotetext{
${ }^{24}$ Desdeñadas por poco reflexivas e insustanciales, frente a la paradigmática belleza artística, e ir casi siempre asociadas al trabajo doméstico femenino o de baja extracción social. Leddy menciona, en este sentido, las tareas del ama de casa, las limpiadoras y los sirvientes como las directamente implicadas en este tipo de propiedades estéticas (Leddy, 1995: 261-262; 2012: 223-225). Contra este descrédito, Saito argumenta la complejidad de dichas propiedades, radicada en su dependencia del contexto en que se presentan, su interés universal -todos nos vemos envueltos, en mayor o menor medida, en ellas- y sus numerosas consecuencias prácticas (éticas, sociales, políticas y/o ecológicas) (Saito, 2007: 153-154).

${ }^{25}$ Como demuestran las conocidas clasificaciones entre artes mayores y artes menores, arte puro y arte aplicado, arte elevado y arte popular, bellas artes y artesanía, etc., a las que se ha referido Larry Shiner como la "gran división" (Shiner, 2004).

${ }^{26}$ Lo confortable e inconfortable - placentero y no placentero, respectivamente, dentro de lo negativo cotidiano- están para él al mismo bajo nivel frente al nivel altísimo de lo fascinante -positivo, por propia definición, en tanto placentero y extraordinario- (Leddy, 2012: 112).
} 
generar complacencia - para eso hay una amplia gama de niveles e intensidades dentro de ella-, en que es sometido a un proceso de depuración de su propia negatividad que le permite devenir indefectiblemente positivo.

\section{Estética cotidiana negativa}

Lo negativo en sentido estricto, sin edulcorantes ni adulteraciones como vemos sobre todo en Leddy, lo negativo con toda su crudeza, en quien tiene propiamente cabida es en Yuriko Saito ${ }^{27}$. Para ella, experiencias mundanas nada complacientes como el elevado sonido de los altavoces en los supermercados o el aire extremadamente contaminado de las ciudades -experiencias irritantes, próximas a la repulsión, si no al asco $-{ }^{28}$, siendo estéticas, pero negativamente, no deben ser canalizadas hacia lo positivo, como ella misma sugiere, por el contrario, en el caso de la porcelana rota de la práctica japonesa del té o el fuerte olor a pescado de los mercadillos ambulantes (Saito, 2007: 171 y 156) ${ }^{29}$; deben conservarse tal cual, en su negatividad intrínseca, por lo mucho que dicen así y lo mucho que pueden inducir de ese modo a actuar. Para desarrollar esta idea, acude la autora a la estética con trasfondo ético, a la "estética social" de Arnold Berleant ${ }^{30}$; o dicho de otro modo, prescinde del desinterés de ascendencia kantiana para devolver a la estética al interés humano y la experiencia general de los que nunca debió ser arrancada. Lejos por eso de un espectador distanciado que formula un juicio estético al margen de los problemas que le rodean, apoya un espectador comprometido, cuyos pronunciamientos estéticos le hagan participar en la mejora de la sociedad; de ahí el papel que reconoce a lo negativo "duro", a lo insultante y lo irrespetuoso por ejemplo, frente a lo simplemente insulso o poco amable -negativos "leves"-, fáciles de conducir hacia lo positivo en su vinculación a la inoperancia y la pasividad estéticas clásicas. Lo negativo "duro", en cambio, lo terminantemente negativo, permite detectar, según Saito, aquellos aspectos de nuestro entorno que, no marchando bien, estimulan

\footnotetext{
${ }^{27}$ Aunque no es la única en asumir los fenómenos estéticos negativos de la cotidianeidad junto a ella, lo hacen también Arnold Berleant y Katya Mandoki-, es la que ofrece una lectura más profunda. Por eso, nos dedicaremos a ella en este apartado.

${ }^{28}$ La autora toma prestados ambos ejemplos de Berleant (Saito, 2017: 215).

${ }^{29}$ Saito reivindica estéticamente aquí el tacto y el olfato respectivamente, en su desprecio consuetudinario frente a la vista y el oído. Ver también, al respecto, Saito, 2007: 21-22.

${ }^{30}$ Esteta de la naturaleza y el medioambiente -no tanto de lo cotidiano-.
} 
a la acción para solventarlos: "la estética de lo cotidiano sería negligente si no admitiese la existencia de una estética negativa a la que ella se debe y para la que explora vías con las que mejorar nuestra vida estética" (Saito, 2017: 216). Sin embargo, esta defensa de lo negativo no significa volver a enraizar la estética en su totalidad en la ética, sino darle a la estética específica de lo cotidiano un perfil instrumental, valerse de ella para optimizar el mundo en que vivimos gracias al inmenso poder que lo estético tiene de facto sobre nosotros; mucho más, asegura Saito, que cualquier argumento de tipo racional ${ }^{31}$.

Es inevitable relacionar en este sentido a Saito con la reflexión de Adorno sobre el arte moderno en clave de la dialéctica negativa que recorre su pensamiento, esto es, con la revisión crítica que el representante de la Escuela de Frankfurt lleva a cabo de todo lo establecido - del proyecto ilustrado, de la sociedad administrada capitalista o del propio arte-, en su propósito de rechazar la voluntad de dominio allí donde se presenta por la privación de libertad y singularidad que conlleva para el individuo. En Adorno, el elemento clave de este programa es, en efecto, el arte, pues como duplicado del mundo y como lugar a la vez de transgresiones, el arte es algo distinto de lo ya conocido, de la sociedad industrial y su uso instrumental de la razón -escribe a propósito de ello el filósofo que el arte, "en todo es como en el estado habitual y sólo un poquito diferente" (Adorno, 2004: 187-188)-. Pero no cualquier arte, sino uno muy determinado: el que prescindiendo de la belleza como consuelo frente a la injusticia y la barbarie, opta por la deformación y el desorden; el que impidiendo su inmediato disfrute y obligando por el contrario a implicarse de veras en él -con el corazón, pero también con la mente y el cuerpo- trabaja por la redención social. Por eso, la disonancia, la estridencia, la fealdad, todo aquello de lo que hace gala y simboliza el arte moderno como arte revolucionario o arte "negativo a priori" (Adorno, 2004: 181), no es una opción estética más para Adorno; es la única opción posible cuando hay que tener presente todo el dolor social acumulado por el desarraigo de una vida más justa y más digna, cuando hay que implicar al hombre como totalidad en la construcción de un mundo más solidario. Más allá de esa fealdad, integrado en los parámetros consabidos de la belleza, el arte deviene aliado del dominio y el sometimiento, pues puesto

\footnotetext{
${ }^{31}$ Remontándose hasta Platón y Aristóteles, la autora insiste en este inigualable "poder de lo estético" -lo llama textualmente así-, por el que nos sentimos animados a actuar por aquello que vemos, sentimos o experimentamos, con independencia de que pueda existir además un programa diseńado ex professo con fines políticos y/o comerciales (Saito, 2007: cap. II; 2017: cap. VII).
} 
a su servicio, hace creer que el gozo es todavía posible, o peor aún, contribuye a ocultar el sufrimiento de una realidad mortalmente herida. Lo inarmónico y desfigurado del arte no es por eso ningún capricho, ninguna actitud intrascendente; es una nueva categoría instalada en el centro mismo del arte que alerta contra la posibilidad indecente e inmoral de seguir invocando el placer en medio del dolor y el sufrimiento.

Aunque la experiencia estética a la que se refiere Saito rompe expresamente con la experiencia vinculada al arte de la que habla Adorno, existe cierta afinidad entre los dos planteamientos en su deseo común de perseverar en lo estéticamente negativo como forma de alcanzar la utopía de lo que en Adorno es una sociedad liberada al fin de la dominación y en Saito, un mundo sencillamente mejor del que hoy por hoy tenemos. Luego sea en las composiciones de Schönberg o los cuadros de Picasso sobre los que reflexiona Adorno, sea en el hilo musical con el que las grandes compañías nos retienen sin pudor al teléfono, como advierte Saito, lo negativo estético nos previene, por un lado, según ambos teóricos, del error que supone esconderlo tras lo positivo -cerrando en falso las heridas, a juicio de Adorno; empobreciendo nuestra calidad de vida, al decir de Saito- y, por otro, de la urgencia de atajar lo mucho que queda por hacer aún hasta la felicidad. Tanto es así que en Adorno, incluso alcanzadas unas condiciones mejores de existencia, superadas la alienación y el sometimiento que han destronado en nuestro tiempo a la belleza y concluida por eso, al menos teóricamente, su misión, lo negativo estético -lo disonante, lo inarmónico, lo estridente- debería seguir existiendo para recordarnos el dolor del que un día brotó; como una manera, en definitiva, de no incurrir en los mismos errores, pues "qué sería el arte como historiografía si se quitase de encima la memoria del sufrimiento acumulado" (Adorno, 2004: 339). En la misma línea, se resiste Saito a una estetización indiscriminada de lo negativo (2007: 203 y 245), inmerso como está en la esfera social e indicándonos así los muchos problemas pendientes todavía en ella. Concluye de ese modo la japonesa, en base a los dos tipos de negativo estético que hemos distinguido en ella -el "duro" y el "leve"-, que uno de los cometidos de la estética de lo cotidiano debería ser precisamente discriminar cuándo estetizar y cuándo no, cuándo dejar lo negativo como negativo y cuándo volverlo, en cambio, positivo, según informe de alguna circunstancia perniciosa - de abandono, de rechazo o indiferencia- para el otro o lo otro que exige una inmediata intervención social ${ }^{32}$.

32 Para Saito, existe un vínculo directo entre la manera de relacionarnos con los seres inanimados, por un lado, y los seres animados, por otro, que tiene además plasmación estética. La 
Sin embargo, fomentando como Adorno la inmutabilidad estética de lo negativo - una parcela del mismo, para ser exactos-, las ideas de Saito guardan cierta similitud también con aquellas de Carolyn Korsmeyer relacionadas con la última explicación de la "paradoja de la tragedia", la integracionista u organicista (Levinson, 2015: 68). Con esta explicación, Korsmeyer ha querido enmendar a las anteriores en su erradicación de los afectos negativos, aplicada en su caso al afecto más negativo de todos: el asco. Ello explica el nombre que recibe esta solución a la negatividad, en su deseo de "integrar" el afecto -suscitado también aquí por el arte, en contraste con el no-arte de Saito-, dentro de la experiencia estética de conjunto, del todo "orgánico" al que pertenece; afecto que se valora y se quiere así, tal cual, en toda su negatividad. La razón que aduce Korsmeyer es que, desde esa negatividad suya y a causa precisamente de ella $-\mathrm{y}$ no, a pesar de ella (Korsmeyer, 2011: 162-163)-, una emoción tan poco afable como el asco -toda emoción dolorosa en realidad-puede llegar a provocar, sorprendentemente, una experiencia estética positiva; de lo que se trata es de reconciliar el estado emocional negativo con la belleza, de la que el asco fue apartado escrupulosamente en el momento de instituirse la estética moderna ${ }^{33}$. En ese sentido y adscribiéndose a la corriente cognitivista en el estudio actual de las emociones ${ }^{34}$, Korsmeyer sostiene que la vis positiva del asco reside en el conocimiento que proporciona, siendo así una especie de trámite necesario del mismo. Haciéndonos conscientes, o simplemente recordándonos, una verdad terrible de la existencia como es nuestra propia condición mortal ${ }^{35}$, la experiencia desagradable del asco sería, como tal, dolorosa, aunque encerraría al mismo tiempo cierto componente de belleza -sería así positiva-. Pero sería una belleza igualmente terrible, difícil, comparada con la belleza del mero disfrute, y con un peso existencial desconocido en la belleza de tipo desinteresado. En suma, que para Korsmeyer el conocimiento de ciertas realidades va estéticamente unido a estados emocionales no placenteros, que como buen acicate para la reflexión, resultan extremadamente convenientes.

estética japonesa sería fiel reflejo de ello (Saito, 2017: 150-184).

33 De ello se encargó Kant, quien por rebajarlo, hasta lo expulsó de algo ya de por sí rebajado como era entonces lo feo: "Sólo una clase de fealdad no puede ser representada conforme a la naturaleza sin echar por tierra toda satisfacción estética, por lo tanto, toda belleza artística, y es, a saber, la que despierta asco (...)” (2001, \$48, 268).

34 Nos referimos a la reciente formulación que reivindica las emociones como parte activa e inteligente del individuo, gracias a lo cual han dejado de tener que estar gobernadas por la razón porque ellas mismas encerrarían cierto componente racional. Es la postura, por ejemplo, de Martha C. Nussbaum (2008).

${ }^{35}$ Para Korsmeyer, el asco es un significante permanente de muerte (2011: 122-124). 
Si bien es cierto que la experiencia estética de Saito tiene mayor alcance que el asco al que se circunscribe Korsmeyer, también lo es que su empeño en la negatividad posee ciertas reminiscencias de la dimensión cognoscitiva que existe en Korsmeyer; sabemos ya que propiedades estéticas cotidianas como insensible y desconsiderado son portadoras para Saito de un hondo contenido social, ético incluso, al que sólo es posible acceder experimentándolas negativamente ${ }^{36}$. Pero esta circunstancia las reviste a la vez de un notable valor positivo -que cohabita así con el negativo, sin reducirlo ni anularlo-, al igual que en Korsmeyer, pues de dichas propiedades depende en última instancia ese desvelamiento decisivo a ojos de Saito para el conjunto social que de otro modo no se daría. El mensaje que se desprende de ello es contundente: la experiencia estética negativa proporciona un conocimiento que no se da en ninguna otra experiencia; esta máxima, sirviéndole primero a Korsmeyer, que la aprovecha para realzar el aspecto más corporal y sensible de la repugnancia, pero también a Saito, que completa el silogismo ańadiendo el paso del conocimiento a la acción, significa que el desagrado, por medio del objeto artístico o del objeto común, dista mucho de aumentar nuestro bienestar; lo altera incluso y produce incomodidad, pero por eso precisamente contiene también una importante lección de vida.

\section{Conclusión}

Queda de manifiesto que al cruzar las emociones negativas con la estética de lo cotidiano se siguen reproduciendo en gran medida los viejos prejuicios de antaño contra el desagrado. Ni siquiera un ámbito presuntamente inclusivo y de reciente gestación como la estética de lo cotidiano es capaz de sustraerse al poderoso sesgo ideológico que, habiendo presidido la disciplina estética durante los dos últimos siglos, ha sometido la experiencia estética a los dictados del disfrute. Como consecuencia de ello, el malestar afectivo causado muchas veces por los objetos comunes y las acciones intrascendentes del día a día sigue sin tener derecho a la existencia y sin ser visibilizado; sigue siendo reorientado así, como se constata en Arto Haapala, Jane Forsey o Parsons y Carlson, hacia el

\footnotetext{
36 Por propiedades como éstas, Saito establece los “juicios estético-morales”, relacionados con virtudes morales originariamente humanas que en el lenguaje corriente solemos atribuir, sin embargo, a artefactos y acciones comunes basándonos en las características perceptivas de su diseño o ejecución (Saito, 2007: 205-242).
} 
terreno de las emociones positivas, hacia el placer y la belleza que, adueñadas de la experiencia estética moderna desde su misma génesis, hicieron desaparecer todo rastro de dolor, de cualquier emoción molesta en realidad susceptible de desmentir la experiencia de tipo superior y privilegiado con la que quedó identificada desde el primer momento la experiencia estética.

La excepción a esta regla la encarna, sin embargo, Yuriko Saito, cuyas tesis representan por eso un avance importante y un desafío palmario al relato estético ortodoxo. En su discurso heterodoxo en torno al fenómeno estético sencillo e irrelevante cotidiano, el displacer es admitido estrictamente como displacer, sin embellecerlo ni sacrificarlo -como sí ocurre, por el contrario, en su colega Thomas Leddy cuando le da supuestamente carta de ciudadanía-. Porque así, al descubierto, en su versión más descarnada o en estado puro, el displacer nos saca de la zona de confort y la pasividad donde nos instaló estéticamente el placer y nos incita a hacer de nuestro mundo un mundo más sostenible y deseable, un mundo que necesita el esfuerzo y la participación de todos para llegar a ser algún día realidad. 


\section{Bibliografía}

Adorno, Theodor W. (2004) [1970]. Teoría estética. Obra Completa 7. Madrid: Akal.

Brady, Emily (2005). "Sniffing and Savoring: The Aesthetics of Smells and Tastes". En A. Light y J. M. Smith (eds.), The Aesthetics of Everyday Life (pp. 177-193). Nueva York: Columbia University Press.

Dewey, John (1949) [1934]. El arte como experiencia. México: FCE.

Diderot, Denis (1994) [1763]. “Antología de los Salones”. En Escritos sobre arte (pp. 45-103). Madrid: Siruela.

Dowling, Chris (2010). "The Aesthetics of Daily Life". British Journal of Aesthetics 50(3), pp. 225-242. doi: 10.1093/aesthj/ayq021

Forsey, Jane (2013a). “Appraising the Ordinary. Tension in Everyday Aesthetics”. Proceedings of the European Society for Aesthetics 5, pp. 237-245. (2013b). The Aesthetics of Design. Oxford: Oxford University Press.

García Yebra, Valentín (2018) [2010]. Poética de Aristóteles. Madrid: Gredos-RBA Libros.

Haapala, Arto (2005). "On the Aesthetics of the Everyday: Familiarity, Strangeness and the Meaning of Place". En A. Light y J. M. Jonathan M. (eds.), The Aesthetics of Everyday Life (pp. 39-55). Nueva York: Columbia University Press.

Hegel, Georg W. F. (2015) [1826]. Filosofía del arte o Estética. Madrid: Abada Editores.

Hume, David (2011) [1757]. "De la tragedia”. En Ensayos morales, politicos y literarios (pp. 211-218). Madrid: Trotta.

Kant, Immanuel (2004) [1790]. Crítica del juicio. Madrid: Espasa-Calpe.

Korsmeyer, Carolyn (2002) [1999]. El sentido del gusto: comida, estética y flosofía. Barcelona: Paidós.

(2011). Savoring Disgust. The Foul and the Fair in Aesthetics. Oxford/Nueva York: Oxford University Press.

Leddy, Thomas (1995). “Everyday Surface Aesthetic Qualities: 'Neat', 'Messy', 'Clean', 'Dirty'". The Journal of Aesthetics and Art Criticism 53(3), pp. 259-268.

(2012). The Extraordinary in the Ordinary. The Aesthetics of Everyday Life. Ontario: Broadview Press. 
Levinson, Jerrold (2015) [2006]. Contemplar el arte. Ensayos de estética. Madrid: Antonio Machado Libros.

Nussbaum, Martha C. (2008) [2001]. Paisajes del pensamiento. La inteligencia de las emociones. Barcelona: Magnum.

Parsons, Glenn y Carlson, Allen (2012) [2008]. Functional Beauty. Oxford: Clarendon Press.

RANCIÈre, Jacques (2012) [2004]. El malestar en la estética. Madrid: Clave Intelectual.

Saito, Yuriko (2017). Aesthetics of the Familiar. Everyday Life and World-Making. Oxford: Oxford University Press. (2007). Everyday Aesthetics. Oxford: Oxford University Press.

Shiner, Larry (2004) [2001]. La invención del arte. Una historia cultural. Barcelona: Paidós.

Silvia, Paul J. (2009). "Looking Past Pleasure: Anger, Confusion, Disgust, Pride, Surprise and Other Inusual Aesthetic Emotions". Psychology of Aesthetics, Creativity and the Arts 3, pp. 48-51. doi: 10.1037/a0014632

Tafalla, Marta (2013). "Anosmic Aesthetics”. Estetika. The Central European Journal of Aesthetics 1, pp. 53-80.

Este trabajo se encuentra bajo una licencia de Creative Commons ReconocimientoNoComercial-SinObraDerivada 4.0 